Research Article

\title{
Quality of life of type 2 diabetes patients in a tertiary care hospital in southern part of India, Shimoga, Karnataka: a cross-sectional study
}

\author{
Santosh Kumar A.*, Raghavendraswamy Koppad, Chandrashekar S. V., Revathy
}

Department of Community Medicine, Shimoga Institute of Medical Sciences, Shimoga, Karnataka, India

Received: 15 May 2016

Revised: 24 May 2016

Accepted: 01 June 2016

\section{*Correspondence:}

Dr. Santosh Kumar A,

E-mail: santu_ar2003@yahoo.co.in

Copyright: ( ) the author(s), publisher and licensee Medip Academy. This is an open-access article distributed under the terms of the Creative Commons Attribution Non-Commercial License, which permits unrestricted non-commercial use, distribution, and reproduction in any medium, provided the original work is properly cited.

\begin{abstract}
Background: Diabetes mellitus is a non-communicable disease which has reached epidemic proportions. According to World Health Organization (WHO) there is "an apparent epidemic of diabetes, which is strongly related to lifestyle and economic change". Objective of the study was to measure the quality of life (QOL) of diabetic patients and to study the various factors influencing the QOL of diabetic patients.

Methods: A hospital based cross sectional study was conducted using medical outcomes study short form version 2 (MOS SF36 v2) to measure the QOL of diabetic patients aged >20 years. 100 diabetics, including 55 males and 45 females were selected.

Results: Mean age of respondents was 54.4 years, with maximum number of subjects in the age group of 40-59 years. $68 \%$ of subjects were form urban area. $63 \%$ of the respondents were having diabetes since 5 years. $91 \%$ of subjects were taking oral hypoglycemic agents (OHA) and 9\% of them were taking both OHA and insulin. Overall, SF 36 scores were lower in females (55.0) than in males (58.47) and this difference was found to be statistically significant. Treatment for diabetes, compliance for treatment, physical activity and follow up with doctor was found to be significantly associated with various domains and total SF-36 scores. Among the eight domains physical functioning and vitality are the domains which were found to be significantly affected.

Conclusions: Diabetes had an adverse effect on QOL of diabetic subjects. With respect to eight domains, males had better scores in almost all domains. Physical functioning (PF), vitality (VT) and overall social functioning (SF)-36 scores were found to be significant.
\end{abstract}

Keywords: Diabetes mellitus, Quality of life, MOS SF36 v2 questionnaire

\section{INTRODUCTION}

Diabetes mellitus is a non-communicable disease which has reached epidemic proportions. According to World Health Organization (WHO) there is "an apparent epidemic of diabetes, which is strongly related to lifestyle and economic change". Diabetes is predicted to become the seventh leading cause of death in the world by the year 2030.Total deaths from diabetes are projected to rise by more than $50 \%$ in the next 10 years. ${ }^{1}$ India is going to become diabetic capital of the world. In India there are 61.3 million people living with diabetes and projected to reach 101.2 million by 2030 with $90 \%$ of cases being type $2 .^{2}$

In 1948 the World Health Organization defined health from a new perspective, stating that health was depending not only by the absence of disease and infirmity, but also by the presence of physical, mental and social wellbeing. ${ }^{3}$ In recent years, there has been a burgeoning interest in quality of life issues, and especially in healthrelated quality of life, fuelled by several factors, including a growing body of evidence concerning the potent effect of psychosocial factors on physical health 
outcomes, and dramatic changes in the organization and delivery of health care.

People with diabetes often feel challenged by their disease and it demands day-to-day management and these demands are substantial. Patients must deal with their diabetes every day, making countless decisions in an effort to approximate the non-diabetic metabolic state. The psychosocial toll of living with diabetes is often a heavy one, and this toll can often, in turn, affect self-care behaviour and ultimately, long-term glycaemic control, the risk of developing long-term complications and quality of life.

The purpose of this study is to throw a light on various dimensions of quality of life of diabetic patients and how various factors like duration of diabetes, treatment and compliance for treatment; complications etc. can affect quality of life (QOL). Understanding these factors that contribute to poor quality of life among people with diabetes may help physicians in improving care. Proper drug therapy, health education, social support and psychological care in diabetes are essential but are usually deficient, especially in developing countries.

\section{METHODS}

The study was conducted at Mcgann Teaching Hospital, Shimoga, India based on hospital based cross sectional study from 1 June 2013 to 30 July 2013. Diabetic patients attending medical OPD in Mcgann hospital were taken as study population.

Diabetic patients aged $>20$ years and on treatment for diabetes for at least 6 months were taken as inclusion criteria.

\section{Exclusion criteria}

- Diabetic patients who did not give consent

- Patients having gestational diabetes

- Patients having Type I diabetes

All diabetic patients attending medical OPD during the study period will be included in the study

A predesigned, pretested semi structured questionnaire was used to collect the information. Informed consent was taken before interviewing the subjects. The detail of this study was explained to the patient and relevant information related to their personal details, clinical history and treatment history was collected. A standardized questionnaire, medical outcomes study short form version 2 (MOS SF36 v2) 4 was used to measure the QOL of diabetic patients. This questionnaire has eight domains namely physical functioning (PF), role physical (RP), bodily pain (BP), general health perceptions (GH), vitality (VT), social functioning (SF), role emotional (RE) and mental health (MH). A separate question about health transition (rating their health in general) is also included in this questionnaire.

Data entry was done in SPSS version 12. The eight domains were scored on a scale of $0-100$, ' 0 ' indicating the worst and ' 100 ' the best possible status. Reverse coding of 10 items was done. Ware et al scoring manual was used for calculating scores. ${ }^{5}$ Raw scale scores were deduced and were finally transformed to a scale of 0100.Appropriate statistical tests were applied to find out the statistical significance.

\section{RESULTS}

In the present study comprising of 100 subjects, 55 (55\%) were males and $45(45 \%)$ were females. With regards to age distribution as shown in Table 1, it was observed that maximum numbers of subjects were in the age group of 40-59 years i.e. $62(62 \%)$ and least number of subjects was observed in the age group of 20-39 years i.e. 4 (4\%). Mean age was observed to be $54.45 \pm 9.7(\mathrm{SD})$ years.

Table1: Distribution of study subjects according to age and sex.

\begin{tabular}{|llllllll|}
\hline $\begin{array}{l}\text { Age } \\
\text { (years) }\end{array}$ & Males & \multicolumn{5}{c|}{ Females } & Total \\
\hline $20-39$ & 2 & 50 & 2 & 50 & 4 & 4 & $20-39$ \\
\hline $40-59$ & 33 & 53.2 & 29 & 46.8 & 62 & 62 & $40-59$ \\
\hline$\geq 60$ & 20 & 58.8 & 14 & 41.2 & 34 & 34 & $\geq 60$ \\
\hline Total & 55 & 55 & 45 & 45 & 100 & 100 & Total \\
\hline
\end{tabular}

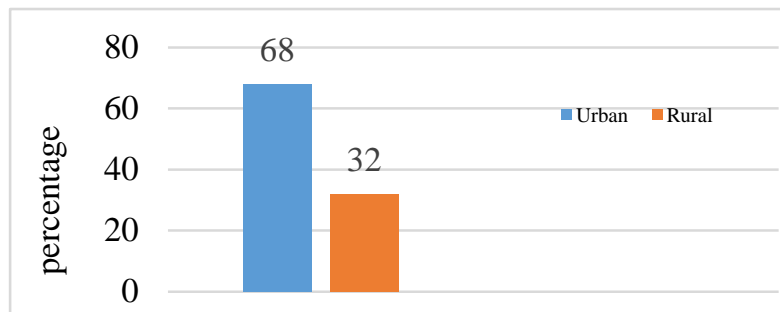

Type of Residence

Figure 1: With respect to residence, most of the study subjects belonged to urban area $(68 \%)$.

In our study $47 \%$ of subjects were illiterate among which $42.5 \%$ were males and rests were females. Among literates only $15 \%$ of subjects had education till high school. Only $3 \%$ of males and $1 \%$ of females had completed degree (Table 2).

Most of the study subjects were having diabetes since 5 years $(63 \%)$ and about $13 \%$ of subjects were having diabetes since 10 years. Mean duration of diabetes was found to be 5.78+4.9 (SD) years, among males it was found to be 5.48 years and among females it was 6.14 years (Table 3 ). 
Table 2: Distribution of study subjects according to their literacy status.

\begin{tabular}{|llllll|}
\hline Literacy status & Males & $\%$ & Females & $\%$ & Number and percentage \\
\hline Illiterates & 20 & 42.5 & 27 & 57.4 & 47 \\
\hline Primary & 9 & 52.9 & 8 & 47.1 & 17 \\
\hline Secondary & 6 & 50 & 6 & 50 & 12 \\
\hline High school & 12 & 80.0 & 3 & 20 & 15 \\
\hline PU & 5 & 100 & 0 & 0 & 5 \\
\hline Degree & 3 & 75 & 1 & 25 & 4 \\
\hline Total & 55 & 55 & 45 & 45 & 100 \\
\hline
\end{tabular}

With respect to treatment, about $91 \%$ of subjects were taking OHA and $9 \%$ of them were taking both OHA and insulin (Table 4). About $80 \%$ of subjects followed some type of dietary modifications for diabetes.

With respect to complications, $48 \%$ of subjects had neuropathy, $6 \%$ had retinopathy and $17 \%$ were not having any type of complications. $91 \%$ of subjects were taking treatment regularly and rests were not regular.
Table 3: Distribution of study subjects according to duration of diabetes mellitus.

\begin{tabular}{|l|ll|ll|}
\hline Duration of diabetes & Males & \multicolumn{2}{c|}{ Females } \\
\hline mellitus (in years) & No & $\%$ & No & $\%$ \\
\hline $1-5$ & 35 & 55.6 & 28 & 44.4 \\
\hline $6-10$ & 14 & 58.3 & 10 & 41.7 \\
\hline$>10$ & 6 & 46.2 & 7 & 13 \\
\hline Total & 55 & 55 & 45 & 45 \\
\hline
\end{tabular}

Table 4: Clinical profile of study subjects.

\begin{tabular}{|c|c|c|c|}
\hline Clinical profile variable & Males (\%) & Females (\%) & Total in percentage \\
\hline \multicolumn{4}{|l|}{ Treatment for DM } \\
\hline OHA & $51(56 \%)$ & $40(44 \%)$ & 91 \\
\hline Insulin & 0 & 0 & 0 \\
\hline Both & $4(44.4 \%)$ & $5(45.0 \%)$ & 9 \\
\hline \multicolumn{4}{|l|}{ Compliance for treatment } \\
\hline Present & $49(53.8 \%)$ & $42(46.2 \%)$ & 91 \\
\hline Absent & $6(66.7 \%)$ & $3(33.3 \%)$ & 9 \\
\hline \multicolumn{4}{|c|}{ Dietary modifications for DM } \\
\hline Present & $4556.2 \%)$ & $35(43.8 \%)$ & 80 \\
\hline Absent & $10(50.0 \%)$ & $10(50.0 \%)$ & 20 \\
\hline \multicolumn{4}{|l|}{ Complications } \\
\hline Absent & $11(64.7 \%)$ & $6(35.3 \%)$ & 17 \\
\hline Neuropathy & $27(56.2 \%)$ & $21(43.8 \%)$ & 48 \\
\hline Retinopathy & $2(33.3 \%)$ & $4(66.7 \%)$ & 6 \\
\hline Nephropathy & 1 & 0 & 1 \\
\hline Others & $14(50.0 \%)$ & $14(50.0 \%)$ & 28 \\
\hline \multicolumn{4}{|l|}{ Comorbidity } \\
\hline Present & $42(53.8 \%)$ & $36(46.2 \%)$ & 78 \\
\hline Absent & $13(59.1 \%)$ & $9(40.9 \%)$ & 22 \\
\hline \multicolumn{4}{|c|}{ Home blood glucose monitoring } \\
\hline Present & $2(40.0)$ & $3(60.0)$ & 5 \\
\hline Absent & $53(55.8 \%)$ & $42(44.2)$ & 95 \\
\hline \multicolumn{4}{|l|}{ Physical activity } \\
\hline Present & $50(56.2 \%)$ & $39(43.8 \%)$ & 89 \\
\hline Absent & $5(45.5 \%)$ & $6(54.5 \%)$ & 11 \\
\hline \multicolumn{4}{|l|}{ Follow up with doctor } \\
\hline Yes & $49(56.3 \%)$ & $38(43.7 \%)$ & 87 \\
\hline No & $6(46.2 \%)$ & $7(53.8 \%)$ & 13 \\
\hline
\end{tabular}


Home blood glucose monitoring was followed by only $5 \%$ of subjects.

Overall, SF 36 scores were lower in females (55.0) than in males (58.47) and this difference was found to be statistically significant. Males had higher scores in most of the domains except $\mathrm{GH}, \mathrm{MH}$ and $\mathrm{HT}$ where it was found to be equal. With respect to PF and VT the difference in scores was found to be statistically significant $(\mathrm{p}<0.05)$ (Table 5).

Table 5: Distribution of SF 36 scores with respect to sex of study subjects.

\begin{tabular}{|lllll|}
\hline \multirow{2}{*}{ SF 36 domains } & $\begin{array}{l}\text { Sex } \\
\text { Male } \\
\text { median (IQR) }\end{array}$ & $\begin{array}{l}\text { Female } \\
\text { median (IQR) }\end{array}$ & $\begin{array}{l}\text { Domain score median } \\
\text { (IQR) }\end{array}$ & $\begin{array}{l}\text { p-value } \\
\text { Physical functioning (PF) }\end{array}$ \\
\hline Role physical (RP) & $35.00(25.00)$ & $60.00(32.50)$ & $72.50(25.00)$ & $0.003 *$ \\
\hline Bodily pain (BP) & $77.50(22.50)$ & $77.50(17.50)$ & $77.50(20.00)$ & 0.237 \\
\hline General health (GH) & $45.00(15.00)$ & $45.00(12.50)$ & $45.00(10.00)$ & 0.236 \\
\hline Vitality (VT) & $62.5(18.75)$ & $50.00(18.75)$ & $56.25(23.43)$ & 0.209 \\
\hline Social functioning (SF) & $87.5(25.00)$ & $75.00(50.00)$ & $81.25(50.00)$ & $0.040^{*}$ \\
\hline Role-emotional (RE) & $33.33(33.33)$ & $25.00(29.16)$ & $33.33(31.25)$ & 0.213 \\
\hline Mental health (MH) & $70.00(25.00)$ & $70.00(45.00)$ & $70.00(28.75)$ & 0.145 \\
\hline Total score & $59.42(13.42)$ & $55.85(22.42)$ & $57.15(18.33)$ & 0.131 \\
\hline
\end{tabular}

*Statistically significant $(\mathrm{p}<0.05)$.

Among the eight domains the most affected were RP and $\mathrm{RE}$ and least affected were $\mathrm{BP}$ and PF. In response to the question about rating their health status as compared to one year ago, most of the subjects (males $65.5 \%$ and females $66.7 \%$ ) reported that it had worsened and $23 \%$ of subjects reported somewhat better than or about the same as one year ago (Table 6).

Table 6: SF 36 scores of study subjects with their factors under study.

\begin{tabular}{|lllllllllll|}
\hline Variables & Domains & PF & RP & BP & GH & VT & SF & RE & MH & HT \\
\hline Age & 0.062 & 0.178 & 0.685 & $0.042^{*}$ & $0.049^{\#}$ & 0.579 & $0.536^{\#}$ & $0.30^{\#}$ & 0.330 & 0.226 \\
\hline $\begin{array}{l}\text { Duration of } \\
\text { diabetes }\end{array}$ & $0.003^{*}$ & 0.205 & 0.158 & 0.323 & $0.02^{*}$ & 0.927 & 0.624 & 0.223 & 0.551 & 0.056 \\
\hline Treatment & 0.390 & $0.348^{\#}$ & 0.388 & 0.954 & $0.023^{*}$ & $0.004^{*}$ & 0.594 & $0.002^{*}$ & $0.595^{\#}$ & $0.002^{*}$ \\
\hline $\begin{array}{l}\text { Patient } \\
\text { compliance }\end{array}$ & $0.001^{*}$ & 0.525 & 0.057 & 0.954 & 0.116 & $0.034^{*}$ & 0.675 & $0.026^{*}$ & 0.931 & $0.000^{*}$ \\
\hline Complications & 0.263 & 0.068 & 0.338 & $0.010^{*}$ & 0.248 & 0.142 & 0.09 & 0.167 & 0.108 & 0.167 \\
\hline $\begin{array}{l}\text { Physical } \\
\text { activity }\end{array}$ & $0.000^{*}$ & $0.209^{\#}$ & 0.015 & 0.245 & 0.029 & 0.003 & $0.204^{\#}$ & 0.002 & $0.351^{\#}$ & $0.000^{*}$ \\
\hline $\begin{array}{l}\text { Dietary } \\
\text { modifications }\end{array}$ & 0.809 & 0.484 & 0.766 & 0.812 & 0.224 & 0.494 & 0.413 & 1.00 & 0.218 & 0.564 \\
\hline Follow up & $0.000^{*}$ & 0.429 & $0.003^{*}$ & 0.994 & $0.006^{*}$ & $0.014^{*}$ & 0.381 & $0.010^{*}$ & 0.153 & $0.000^{*}$ \\
\hline
\end{tabular}

\# Fishers exact test used. *Statistically significant ( $\mathrm{p}<0.05$ )

SF 36 scores and its eight domains when compared with various socio demographic variables and clinical profile, significant associations were observed. Overall SF 36 score was significantly associated with type of treatment, patient compliance with treatment, physical activity and follow up with doctors. Among the eight domains, PF and VT were associated with duration diabetes.

$89 \%$ of subjects were following some type of physical activity and about $87 \%$ of subjects were having regular follow up with doctor. The most common co morbidity was hypertension $(57 \%)$ and $12 \%$ of them were having both hypertension and ischemic heart disease.

\section{DISCUSSION}

In the present study 100 diabetic subjects (Type II diabetes) were interviewed regarding quality of life. 
Maximum numbers of subjects were in the age group of 40-59 years i.e. $62(62 \%)$ and this is in consistent with the pattern of diabetes observed in developing countries. Most of the study subjects were having diabetes since 5 years $(63 \%)$ and about $13 \%$ of subjects were having diabetes since 10 years. Mean duration of diabetes was found to be $5.78 \pm 4.9$ (SD) years, among males it was found to be 5.48 years and among females it was 6.14 years. Subratty et al and Okanovic et al study reported mean duration of diabetes in their study subjects of 9.3 \pm 7.7 years and 10.2 \pm 6.2 years respectively. ${ }^{6,7} \mathrm{M}$. Riaz et al study also revealed mean duration diabetes of $8.88 \pm 6.91$ years. $^{8}$ Most common complication in our study subjects was found to be neuropathy (48\%) and it is consistent with the findings reported by other authors. Jacobson et al found $48.8 \%$ of their study subjects to be having neuropathy. Mayou et al found $20 \%$ with neuropathy. ${ }^{9,10}$

Table 5 depicts the median and interquartile range for the eight domains scores and for overall SF 36 scores with respect to sex of the study subjects. The scores for males was found to be higher in almost all domains, SF 36 score was also found to be higher in males compared to females. This difference was found to be statistically significant in PF, VT and for overall SF 36 scores ( $p$ <0.05). Gautam et al study done in diabetic clinics in Delhi also reported the similar findings. ${ }^{11}$ In another study by Chittleborough et al done in Australian population reported similar finding where QOL scores among males were higher in all domains (except $\mathrm{GH}$ and VT). ${ }^{12}$ Angelos A et al study in Greece also showed statistically significant lower QOL scores in females, specifically PF, BP, VT and SF similar to our study. ${ }^{13}$

A study in UK by Woodcock et al also reported better scores for males in all domains, except in BP. ${ }^{14}$ Glassgow et al study on 2800 adults with diabetes in US also reported significantly higher scores in males. ${ }^{15}$ The reasons for this could be that males may have regular contact with health care services and are more compliance for treatment compare to females.

In Table 6, age was found be significantly associated with GH and VT. Similar to our findings Kazemi-Glaougahi $\mathrm{MH}$ et al study reported reverse correlation with PF, VT and $\mathrm{MH} .{ }^{16}$ With respect to duration of diabetes PF and VT was found to be statistically significant. All domains revealed better scores except RE, RP and GH. This may be due to improvement in these domains due to adaptation of diabetic life style, rest of the domains had opposite effect. Woodcock et al also noted that patients with more than 5 years duration of diabetes had better scores in all domains, except BP. ${ }^{14}$ Whereas in KazemiGlaougahi $\mathrm{MH}$ et al no correlation was observed between duration of diabetes and QOL domains. ${ }^{16}$

Patients who were taking only OHA had better scores compared to who were taking both $\mathrm{OHA}$ and insulin. The domains VT, SF, MH and total SF 36 scores were found to be significantly associated. Cheah WL et al study reported that respondents taking insulin had significantly lower adjusted mean scores in role-physical $(\mathrm{p}=0.014)$ and bodily pain $(\mathrm{p}=0.026)$ components compared with respondents taking less than three oral drugs. Similarly Redekop et al found that insulin therapy is one of the factors that lead to lower health-related quality of life. Injection of insulin injections may create fear and have adverse effects, such as hypoglycaemia which may lead to poor QOL scores. ${ }^{17,18}$

Patients who took regular treatment had better QOL scores in PF, SF and MH. Overall SF 36 scores was also found to be significant. Wisit et al study reported compliance for drug intake to be significantly associated with QOL $(p<0.05) .{ }^{19}$ Adherence to treatment leads to good glycaemic control which in turn improves the QOL of diabetic patients.

With respect to complications, GH was significantly affected compare to other domains. In Gautam et al study overall scores was less among respondents with complications and this difference was significant. Similarly Woodcock et al also reported bad scores in subjects having complications. ${ }^{11,14}$

Physical activity was found to be strongly associated with overall SF 36 scores and in particularly domains of PF, $\mathrm{BP}, \mathrm{MH}, \mathrm{VT}$ and SF. Low level of physical activity was found to be associated with poor QOL scores. This is in consistent with other studies, in Glasgow et al study low level of physical activity was associated with poor QOL scores and also a randomized controlled trial by Myers $\mathrm{VH}$ et al also reported good QOL scores (physical component subscale and the general health subscale) in type 2 diabetics who were given exercise training compare to control group. ${ }^{15,20}$

With respect to regular follow up with doctor, most of the subjects had better scores and was significantly associated with domains of PF, BP, VT and MH. Overall SF 36 scores were also found to be significant. This is in consistent with the study by M Riaz et al in which QOL of life was better in patients who had regular follow up. ${ }^{8}$ Regular follow up with doctor will make the patient to take treatment regularly and it also helps the doctor to give diabetes related health education more frequently to the patients.

\section{CONCLUSION}

In our study, number of males was slightly higher than females. Majority of them belonged to age group of 4059 years. Majority of subjects were Hindus. The literacy percentage was slightly higher in males than in females. Majority of the respondents when asked about their general health status responded that somewhat worse compared to one year ago. In most of the domains males had better scores compared to females and overall SF 36 scores was also found to be better in males. Treatment for 
diabetes, compliance for treatment, physical activity and follow up with doctor was found to be significantly associated with various domains and total SF-36 scores. As the duration of diabetes increased most of the domains were having better scores due to adaptation of diabetic life style. Presence of any complications was significantly associated with GH and RE. Among the eight domains physical functioning and vitality are the domains which were found to be significantly affected. By this study we can conclude that regular medications, physical activity of a minimum 30 minutes per day, compliance for treatment and regular follow up are most important factors in improving the QOL in diabetics. Since diabetes is a chronic disease and it has reached epidemic proportions in India we suggest further studies with a large sample size, preferably with a comparison group of non-diabetic subjects to generalize our findings.

\section{ACKNOWLEDGEMENTS}

We would like to thank all patients of McGann Hospital for their co-operation during this study.

Funding: No funding sources

Conflict of interest: None declared

Ethical approval: The study was approved by the Institutional Ethics Committee

\section{REFERENCES}

1. WHO. World health organisation. 10 Facts about diabetes. Available from http:// www.who.int/ features/factfiles/diabetes/facts/en/index1.html. Accesed on 20 January 2013.

2. IDF.International Diabetes Federation. Available from http://www.idf.org/diabetesatlas/5e/the-globalburden. Accessed on 21 January 2013.

3. Constitution of the World Health Organization. In Handbook of Basic Documents, World Health Organization, $5^{\text {th }}$ edition. Geneva: Palais des Nations:1952;3-20.

4. SF-36. A community for measuring health outcomes using SF tools. Available from http://www.sf36.org/tools/s\# Fishers exact test used. * Statistically significant (p <0.05) f36.shtml. Accessed on 25 September 2013.

5. Ware JE, Sherbourne CD. The MOS 36 item shortform health survey (SF-36) - conceptual framework and item selection. Med Care. 1992;30:473-81.

6. Subratty AH. Quality of life of people with type 2 diabetes in Mauritius-research. Quality of life research 2004. Available from www.findarticles.com. Accessed on 25 september 2013.

7. Pibernik OM. Psychometric properties of the World Health Organization quality of life questionnaire (WHOQOL-100) in diabetic patients in Croatia. Diabetes Res ClinPract. 2001;51:133-43.
8. Riaz M, Rehman RA, Hakeem R, Shaheen F. Health related quality of life in patients with diabetes using SF-12 questionnaire. J Diabetol. 2013;2:1-7.

9. Jacobson AM, Groot M, Samson JA. The evaluation of two measures of quality of life in patients with type I and type II diabetes. Diabetes care. 1994; 17:267-74.

10. Mayou R, Bryant B, Turner R. Quality of life in non-insulin dependent diabetes and a comparison with insulin-diabetes. J Psychosom res. 1990;34:111.

11. Gautham. A cross-sectional study of QOL of diabetic patients at tertiary care hospitals in Delhi. Indian journal of Community Medicine. 2009;34(4):346-50.

12. Chittleborough CR, Baldock KL, Taylor AW, Phillips PJ. North west adelaide health study team. health status. Assessed by the SF-36 along the diabetes continuum in an Australian population. Qual Life Res. 2006;15:687-94.

13. Papadopoulos AA, Kontodimopoulos N, Frydas A, et al. Predictors of health-related quality of life in type II diabetic patients in Greece. BMC Public Health. 2007;7:186.

14. Woodcock AJ, Julious SA, Kinmonth AL, Campbell MJ. Diabetes care from diagnosis group. problems with the performance of the sf-36 among people with type 2 diabetes in general practice. Qual Life Res. 2001;10:661-70.

15. Glasgow RE, Ruggiero L, Eakin EG, Dryfoos J, Chobanian L. Quality of life and associated characteristics in a large national sample of adults with diabetes. Diabetes Care. 1997;20:562-67.

16. Kazemi GMH, Navidi GH, Eftekhar AH, Mahmoudi H. Quality of life in type 2 diabetic patients and related effective factors. Indian $\mathbf{J}$ Med Sci. 2012;66(9):230-7.

17. Cheah WL, Lee PY, Lim PY. Perception of quality of life among people with diabetes. Malaysian Family Physician. 2012;7(2):21-30.

18. Redekop WK, Koopmanschap MA, Stolk RP. Health related quality of life and treatment satisfaction in Dutch patients with type 2 diabetes. Diabetes Care. 2002;25(3):458-63.

19. Wisit C, Natchaporn P, Frank PS, Udomsak M. Quality of life and compliance among type 2 diabetic patients. Southeast Asian Jour of Trop Med Public Health.2008;39(2):328-34.

20. Myers VH. Exercise training and quality of life in individuals with type 2 diabetes. Diabetes Care. 2013;36(7):1884-90.

Cite this article as: Kumar SA, Koppad R,

Chandrashekar SV, Revathy. Quality of life of type 2 diabetes patients in a tertiary care hospital in southern part of India, Shimoga, Karnataka: a cross-sectional study. Int J Community Med Public Health 2016;3: 1723-8. 